\title{
Diferentes protocolos de desinfecção do alginato contaminado com $C$. albicans
}

\author{
Different disinfection protocols for alginate contaminated with C. albicans
}

Diferentes protocolos de desinfección de alginatos contaminados com C. albicans

Aghata Kelma Palacio Gomes ${ }^{1 *}$, Camila Alves Garcia², Hellen Martins Juca², Steffani Vasconcelos Santos $^{2}$, Karina Matthes de Freitas Pontes ${ }^{1}$, Bruna Marjorie Dias Frota de Carvalho².

\section{RESUMO}

Objetivo: Avaliar a eficácia de diferentes métodos de desinfecção de alginato contaminado com Candida albicans (C. albicans) através do uso de ácido peracético 0,2\%, alecrim-pimenta (Lippiasidoides cham.), digluconato de clorexidina $2 \%$ e hipoclorito de sódio 1\%. Métodos: Biofilmes de C. albicans ATCC 10231 foram desenvolvidos por $48 \mathrm{~h}$. Na sequência, discos de alginato (Hydrogum 5) foram contaminados com $C$. albicans por 3 minutos sendo submetidos à desinfecção por pulverização (spray) por 10 min, exceto pelos discos dos grupos controle (apenas contaminação) ou de lavagem inicial. A quantificação celular foi realizada após o tempo de contaminação imediata e após 5 dias. Os dados foram submetidos à análise de variância (ANOVA) seguido do teste de Tukey $(\alpha=0,05)$. Resultados: Os discos apenas contaminados apresentaram o maior crescimento de $C$. albicans na análise imediata e tardia $(p<0,05)$. Os discos apenas com lavagem inicial apresentaram maior crescimento de microrganismos em relação aos que foram desinfetados, independente do tempo de análise $(p<0,05)$. Quanto aos discos desinfetados, não houve crescimento de microrganismos, independente do agente utilizado e tempo de análise $(p>0,05)$. Conclusão: $O$ sprayde ácido peracético, alecrim-pimenta, digluconato de clorexidina e hipoclorito de sódio apresentaram, portanto, poder fungicida na desinfecção de moldes de alginato.

Palavras-chave: Desinfecção, Hidrocolóide irreversível, Terapias alternativas.

\begin{abstract}
Objective: To evaluate the efficiency of different methods of disinfecting alginate contaminated with Candida albicans (C. albicans) through the use of $0.2 \%$ peracetic acid, pepper rosemary (Lippiamenosides cham.), Chlorhexidine digluconate $2 \%$ and sodium hypochlorite $1 \%$. Methods: Biofilms of C. albicans ATCC 10231 were developed for $48 \mathrm{~h}$. Then, alginate discs (Hydrogum 5) were contaminated with $C$. albicans for 3 minutes and were subjected to disinfection by spray for $10 \mathrm{~min}$, except for the discs of the control groups (only contamination) or initial wash. Cell quantification was performed after the time of immediate contamination and after 5 days. The data were submitted to analysis of variance (ANOVA) followed by the Tukey test $(\alpha=0.05)$. Results: The only contaminated discs showed the highest growth of $C$. albicans in the immediate and late analysis $(p<0.05)$. The discs with only initial washing showed a higher growth of microorganisms in relation to those that were disinfected, regardless of the analysis time $(p<0.05)$. As for disinfected disks, there was no growth of microorganisms, regardless of the agent used and time of analysis $(p>0.05)$. Conclusion: The spray of peracetic acid, pepper rosemary, chlorhexidine digluconate and sodium hypochlorite showed, therefore, fungicidal power in the disinfection of alginate molds.
\end{abstract}

Keywords: Disinfection, Irreversible hydrocolloid, Alternative therapies.

1 Universidade Federal do Ceará (UFC), Fortaleza - CE. *E-mail: aghatapalacio@alu.ufc.br

${ }^{2}$ Centro Universitário Christus (Unichristus), Fortaleza - CE.

SUBMETIDO EM: $3 / 2021$

ACEITO EM: $3 / 2021$

PUBLICADO EM: 4/2021 


\section{RESUMEN}

Objetivo: Evaluar la eficacia de diferentes métodos de desinfección de alginato contaminado con Candida albicans (C. albicans) utilizando ácido peracético al 0,2\%, pimienta romero (Lippiasidoides cham.), Digluconato de clorhexidina al $2 \%$ e hipoclorito de sodio al 1\%. Métodos: Se desarrollaron biopelículas de C. albicans ATCC 10231 durante 48 h. Luego, los discos de alginato (Hydrogum 5) se contaminaron con C. albicans durante 3 minutos y se sometieron a desinfección por aspersión (spray) durante 10 min, a excepción de los discos de los grupos control (solo contaminación) o lavado inicial. La cuantificación celular se realizó después del momento de la contaminación inmediata y después de 5 días. Los datos se sometieron a análisis de varianza (ANOVA) seguido de la prueba de Tukey $(\alpha=0.05)$. Resultados: Los únicos discos contaminados mostraron el mayor crecimiento de $C$. albicans en el análisis inmediato y tardío $(p<0.05)$. Los discos con solo lavado inicial mostraron un mayor crecimiento de microorganismos en relación a los que fueron desinfectados, independientemente del tiempo de análisis $(p<0.05)$. En cuanto a los discos desinfectados, no hubo crecimiento de microorganismos, independientemente del agente utilizado y el tiempo de análisis $(p>0,05)$. Conclusión: La aspersión de ácido peracético, pimienta romero, digluconato de clorhexidina e hipoclorito de sodio mostró, por tanto, poder fungicida en la desinfección de mohos alginatos.

Palabras clave: Desinfección, Hidrocoloide irreversible, Terapias alternativas.

\section{INTRODUÇÃO}

$\mathrm{Na}$ Odontologia, há uma necessidade contínua de conhecimento sobre o uso de novas abordagens e como reproduzir com fidedignidade os tecidos orais utilizando um material preciso e técnica eficaz para fornecer o processo de tratamento dentário adequado (JUNEVICIUS J, et al., 2004; ULGEY M, et al., 2020). Frequentemente, novas tecnologias e materiais são introduzidos aos profissionais da Odontologia, embora os materiais e técnicas convencionais ainda sejam preferidos em clínicas e laboratórios (JUNEVICIUS J, et al., 2004).

Nesse contexto, o alginato ou hidrocolóide irreversível é um dos materiais de moldagem mais utilizados na Odontologia convencional e é normalmente utilizado para a produção inicial de próteses dentárias totais ou parciais imediatas/provisórias (KAKATKAR VR, 2013; PUNJ A, et al., 2017; ULGEY M, et al., 2020). Dentre as vantagens desse material, se encontram boas propriedades de umedecimento, facilidade de manipulação, baixa sensibilidade técnica, compatibilidade com material fundido, hidrofilicidade, sabor e odor agradáveis, baixo custo, longa vida útil e melhor escolha para fabricar modelos diagnósticos (AL MORTADI N, et al., 2019).

Porém, por ser hidrofílico, o alginato apresenta a propriedade de embebição que faz com que os microrganismos penetrem com maior facilidade no interior do molde juntamente com os fluidos absorvidos, servindo como meio de contaminação cruzada entre pacientes e profissionais por meio de bactérias e fungos (OSÓRIO AM, 1998; REUGGEBERG FA, 1992; AL MORTADI N, et al., 2019). Diante disso, ressalta-se a importância da desinfecção desse material no intuito de reduzir a chance de infecções (ULGEY M, et al., 2020; MINAGI S, et al., 2012).

Os agentes desinfetantes mais descritos na literatura para a desinfecção de moldes de alginato são o glutaraldeído (2\%) e o hipoclorito de sódio (1\%). Porém, ambas soluções apresentam desvantagens, como a elevada toxicidade, alteração dimensional e a incompatibilidade com as moldeiras utilizadas (MEIRA DM, et al., 2011). Além disso, o uso do glutaraldeído foi proibido em alguns estados brasileiros devido a sua inalação poder causar danos à saúde (GUIRALDO RD, et al., 2012).

O hipoclorito de sódio é um potente agente desinfetante e é muito utilizado na desinfecção de impressões. Segundo Choudhury GK, et al. (2018), o hipoclorito de sódio tem eficácia na desinfecção do alginato contra C. albicans, $P$. aeruginosa e $S$. Aureus. Porém, é inativado por matéria orgânica e considerado prejudicial ao meio-ambiente (DASCHNER F,1997; CHOUDHURY GK, et al., 2018). 
O digluconato de clorexidina, é uma biguanida catiônica, uma base forte que em altas concentrações tem efeito bactericida e em baixas concentrações tem efeito bacteriostático. Essa substância tem sido muito utilizada na Odontologia por sua substantividade, ação antimicrobiana e biocompatibilidade. Recentemente, a clorexidina vem sendo muito utilizada para a desinfecção dos moldes de alginato e tem sido comparada em vários estudos com outras substâncias desinfetantes, e uma das suas desvantagens é não ter atividade solvente sobre tecidos quando comparadas a outras substâncias, como o hipoclorito de sódio (MARION J, et al., 2013).

Também disponível, o ácido peracético é uma combinação de ácido acético, peróxido de hidrogênio e água e é um agente desinfetante de amplo espectro de ação microbiana (GRAZIANO KU, et al., 2000). Essa substância tem como vantagem não ser inativado na presença de matéria orgânica e não gerar resíduos tóxicos para o meio ambiente e vem sendo testada como alternativa ao uso do glutaraldeído e hipoclorito de sódio para a desinfecção de moldes (BORGES LC, 2006; STAMPI S, 2001; STAMPI S, et al., 2002).

O Lippiasidoides Cham (L. sidoides)., mais conhecido como alecrim-pimenta, é um arbusto silvestre originário do nordeste brasileiro que possui propriedades antimicrobianas e anti-sépticas (PASCUAL ME, et al., 2001). Pertencente à família Verbenacea, o alecrim-pimenta é um arbusto muito ramificado e quebradiço, de 2-3 m de altura, próprio da vegetação do semi-árido nordestino e suas folhas juntamente com as flores constituem a parte medicinal desta planta, usada na forma de chá (MATOS FJ, et al., 1998).

$\mathrm{Na}$ análise fitoquímica foi constatado que esta espécie possui óleo essencial rico em timol, carvacrol e pcimeno, por exemplo. (MATOS FJ, et al., 1998; DE VASCONCELLOS AJ, et al., 2014). Nesse contexto, é importante ressaltar que Timol tem sido reconhecido como o composto ativo relacionado à propriedade antibacteriana e antifúngica do óleo essencial de L. sidoides (MATOS FJ, et al., 1998; DE VASCONCELLOS AJ, et al., 2014).

Por meio disso, é importante ressaltar que a desinfecção dos materiais de moldagem pode ser realizada por imersão ou pulverização. Utilizando o método de imersão, a substância utilizada atinge uma maior superfície de contato do que o método de pulverização. Entretanto, o segundo método apresenta menores índices de alteração dimensional, não existindo, porém, uma padronização universal quanto ao método e a substância ideal para a desinfecção dos materiais de moldagem (REUGGEBERG FA, 1992; ULGEY M, et al., 2020; AL MORTADI N, et al., 2019; AMALAN A, et al., 2013).

Assim, o objetivo desse estudo foi avaliar o real poder fungicida de diferentes protocolos de desinfecção, a fim de que possam ser utilizados na Odontologia como meio seguro para desinfetar moldes de alginato, trazendo benefícios significativos para trabalhadores da área e pacientes.

\section{MÉTODOS}

\section{Delineamento experimental}

Foram confeccionadas 420 matrizes com hidrocolóide irreversível $(n=10)$. Os discos foram então contaminados com cultura contendo $C$. albicanse passaram por processo de desinfecção. Os desinfetantes selecionados foram o ácido peracético 0,2\%, o alecrim pimenta (LippiasidoidesCham.), digluconato de clorexidina $2 \%$ e hipoclorito de sódio $1 \%$, todos em formato de spray, por 10 minutos. Os discos foram divididos em 12 grupos, a análise microbiológica foi imediata em seis grupos e, após 120 horas, nos outros seis. Após o processo, foi realizada análise microbiológica para quantificação de células de $C$. albicans viáveis por meio da contagem de UFC/mL.

\section{Obtenção dos extratos}

A matéria prima (folhas) da Lippiasidoides Cham, no início da floração, foi coletada no Horto de plantas medicinais da Farmácia Viva da Universidade Federal do Ceará (UFC) e foram secas em estufas a $40^{\circ} \mathrm{C}$. A obtenção dos extratos foi realizada no Laboratório de Farmacotécnica da Faculdade de Farmácia, Odontologia e Enfermagem (FFOE) da UFC. 
Para extração, foi empregado o método de lixiviação em fluxo contínuo à temperatura ambiente. A extração ocorreu através da solução extratora de álcool metanol (a $80 \% \mathrm{v} / \mathrm{v})$, renovada constantemente por um período de 24 horas, pela qual se obteve um concentrado a $500 \mathrm{~mL}$. Para identificação dos compostos presentes no óleo essencial foi realizada análise cromatográfica (Agilent Technologies, Santa Clara, Estados Unidos). Foi realizada por comparação do espectro de massas com os espectros da biblioteca NIST MS 2.0 e da literatura (DE VASCONCELLOS AJ, et al., 2014). Calculou-se o índice de retenção relativa dos compostos a partir do tempo de retenção de uma mistura de n-alcanos (C7-C40, Sigma USA) 20ppm, split 1:100 (DE VASCONCELLOS AJ, et al., 2014).

\section{Confecção dos corpos de prova de alginato}

Para avaliar cada desinfetante, foram confeccionados corpos de prova de alginato Hydrogum 5 (ZhermackBrasil). Com uma espátula plástica e um gral de borracha desinfetados com solução de álcool $70 \%$ (três aplicações), o alginato foi manipulado seguindo rigorosamente as instruções do fabricante. Após cerca de 60 segundos de espatulação, o alginato foi inserido em uma seringa descartável $5 \mathrm{cc}$ estéril. Após a geleificação, o material foi removido e recortado utilizando lâminas de bisturi no 10 e paquímetro digital (Marberg 150MM), formando discos de espessura de $3 \mathrm{~mm}$ (CLINICAL AND LABORATORY STANDARDS INSTITUTE, 2008). Os discos cortados foram divididos aleatoriamente em 12 grupos, possuindo cada grupo 10 amostras. A pesquisa foi realizada em triplicata.

\section{Desenvolvimento do biofilme}

C. albicans ATCC 10231 foram reativadas em placas de Ágar Sabouraud Dextrose (Difco, Detroit, USA) a $\pm 35 \stackrel{\circ}{\circ}$, durante 24 horas. Colônias do produto da reativação foram coletadas com uma alça estéril em 2 tubos Falcon, contendo $10 \mathrm{~mL}$ de meio de cultura líquido YNB (Difco, Detroit, USA) suplementado com 50 $\mathrm{mM}$ de glicose. Os tubos foram, então, incubados em estufa, sob agitação a $\pm 35 \stackrel{\circ}{\circ}$, por 18-20 $\mathrm{h}$, fase de crescimento exponencial desses microrganismos (CLINICAL AND LABORATORY STANDARDS INSTITUTE, 2008).

Após este período, os tubos passaram por centrifuga por 5 minutos a $3.500 \mathrm{rpm}$ em temperatura ambiente. Depois disso, as células foram "lavadas" duas vezes com $10 \mathrm{~mL}$ de PBS estéril ( $\mathrm{NaCl} 137 \mathrm{mM}$, Fosfato 10 $\mathrm{mM}, \mathrm{KCl} 2.7 \mathrm{mM}$, e um pH de 7.4), sendo novamente centrifugadas no intervalo de cada "lavagem". Em seguida, uma alíquota de células centrifugadas foi adicionada a 2 tubos contendo YNB suplementado com $100 \mathrm{mM}$ de glicose (30 mL para cada). A suspensão de células foi ajustada opticamente através de um espectrofotômetro a uma densidade correspondente a $10^{7}$ células $/ \mathrm{mL}$ (D.O. 0.38) (DE FREITAS-PONTES $\mathrm{KM}$, et al., 2014).

Uma suspensão de $150 \mu \mathrm{L}$ do inóculo de $C$. albicans foi transferida para placas de 24 poços, contendo 2 $\mathrm{mL}$ de SabouraudBroth. Estas placas foram incubadas em estufa a $\pm 35^{\circ} \mathrm{C}$ sob agitação constante por 90 minutos, tempo este correspondente à fase de adesão celular. Após o período de adesão, as células contidas em cada poço foram lavadas com $2 \mathrm{~mL}$ de PBS estéril para a remoção de células não aderidas. Na sequência, $2 \mathrm{~mL}$ de meio de cultura fresco, SabouraudBroth foram acrescentados em cada poço. As placas foram novamente incubadas a $\pm 35 \stackrel{\circ}{\circ}$, sob agitação constante, por 24 horas. Após esse período, houve nova lavagem das células, e o meio de cultura foi substituído. As placas foram incubadas por mais 24 horas.

\section{Contaminação e desinfecção dos corpos de prova}

Após 48 horas de desenvolvimento do biofilme, uma alíquota de cada poço foi utilizada para a contaminação dos discos de alginato, a qual ficou em contato com o disco por um período de 3 minutos.

Após a etapa de contaminação, os discos foram aleatoriamente divididos em seis grupos, conforme descrito na Tabela 1. Cada grupo foi composto por dez discos. Os grupos controle (GN) passaram por análise imediata e após 5 dias, os quais foram apenas contaminados. Os grupos lavagem (GL) passaram pela contaminação e pela lavagem inicial. 
Tabela 1 - Descrição dos grupos do estudo conforme as etapas de contaminação, lavagem inicial, desinfecção e lavagem final, com análise microbiológica imediata e após 5 dias.

\begin{tabular}{ccccc}
\hline Grupos & Contaminação & $\begin{array}{c}\text { Lavagem } \\
\text { Inicial }\end{array}$ & $\begin{array}{c}\text { Spray 10 } \\
\text { minutos }\end{array}$ & $\begin{array}{c}\text { Lavagem } \\
\text { Final }\end{array}$ \\
\hline 1. Controle Negativo (GN) & $\mathrm{V}$ & - & - & - \\
2. Grupo Lavagem (GL) & $\mathrm{V}$ & $\mathrm{V}$ & - & - \\
3. Grupo Lippiasidoides (GLS) & $\mathrm{V}$ & $\mathrm{V}$ & $\mathrm{V}$ & $\mathrm{V}$ \\
4. Grupo Ácido Peracético 0,2\% (GAP) & $\mathrm{V}$ & $\mathrm{V}$ & $\mathrm{V}$ & $\mathrm{V}$ \\
5. Grupo Digluconato de clorexidina 2\% (GCL) & $\mathrm{V}$ & $\mathrm{V}$ & $\mathrm{V}$ & $\mathrm{V}$ \\
6. Grupo Hipoclorito de sódio 1\% (GHP) & $\mathrm{V}$ & $\mathrm{V}$ & $\mathrm{V}$ & $\mathrm{V}$ \\
\hline
\end{tabular}

Legenda: V: presença; -: ausência.

Fonte: Gomes AKP, et al., 2021.

Antes do processo de desinfecção, utilizando o desinfetante na forma de spray, os discos passaram pela lavagem inicial com $2 \mathrm{~mL}$ de água destilada estéril. Os discos foram inseridos, totalmente imersos e removidos da água. Na forma de spray, o líquido foi borrifado com exatamente 3 pulverizações em todo o processo sobre superfície estéril. Após a utilização do spray, por 10 minutos, foi realizada a segunda lavagem exatamente igual à primeira lavagem.

Foi realizada quantificação imediata e após período de 120 horas (5 dias) das células de $C$. albicans. Nos grupos avaliados após 120 horas de contaminação e desinfecção, os discos ficaram armazenados no interior de uma placa de 24 poços a temperatura ambiente, a fim de evitar perda da solução desinfetante e sinérese do alginato. Três compressas de gaze estéril foram diariamente umedecidas e trocadas até o momento da análise microbiológica.

A quantificação de células viáveis foi realizada através do método de diluição decimal seriada. Para isso, os discos foram transferidos para tubos Falcon contendo $3 \mathrm{~mL}$ de PBS. Em seguida, este conjunto foi levado ao sonicador por 30 segundos a $7 \mathrm{~W}$ de potência, a fim de remover o biofilme da superfície do disco e também desagregar as células unidas entre si. Após a dispersão celular dos biofilmes, este conteúdo foi submetido à diluição decimal seriada e três gotas de $25 \mu \mathrm{L}$ de cada diluição foram semeadas em triplicata em placas de Ágar Sabouraud Dextrose. As placas foram incubadas a $\pm 35 \stackrel{\circ}{\circ}$ por 24 horas. As colônias foram visualmente quantificadas e utilizadas para determinar o número de células presentes no biofilme, sendo o resultado expresso em células/mL.

\section{RESULTADOS}

Os dados foram submetidos à análise de variância (ANOVA one-way) seguido do teste de Tukey $(\alpha=0,05)$. Os discos apenas contaminados apresentaram o maior crescimento de $C$. albicans na análise imediata e tardia $(p<0,05)$. Os discos apenas com lavagem inicial apresentaram maior crescimento de microrganismos em relação aos que foram desinfetados, independente do tempo de análise $(p<0,05)$. Quanto aos discos desinfetados, houve redução do crescimento de microrganismos, independente do material utilizado e tempo de análise $(p<0,05)$.

Os grupos tratados com clorexidina (GCL), hipoclorito (GHP), ácido peracético (GAP) e extrato de Lippiasidoides (GLP) apresentaram melhor poder antifúngico $(\mathrm{p}<0,001)$ ao serem comparados com os grupos controles negativos (GN) e somente lavados inicialmente (GL). Tanto em análise imediata quanto após 120 horas. Os resultados podem ser visualizados nos Gráficos 1 e 2. 
Gráfico 1 - Quantidade de células (células $/ \mathrm{mL}$ ) de C. albicans ATCC 10231 após contaminação e tratamento com diferentes soluções desinfectantes em discos de alginato, de forma imediata.

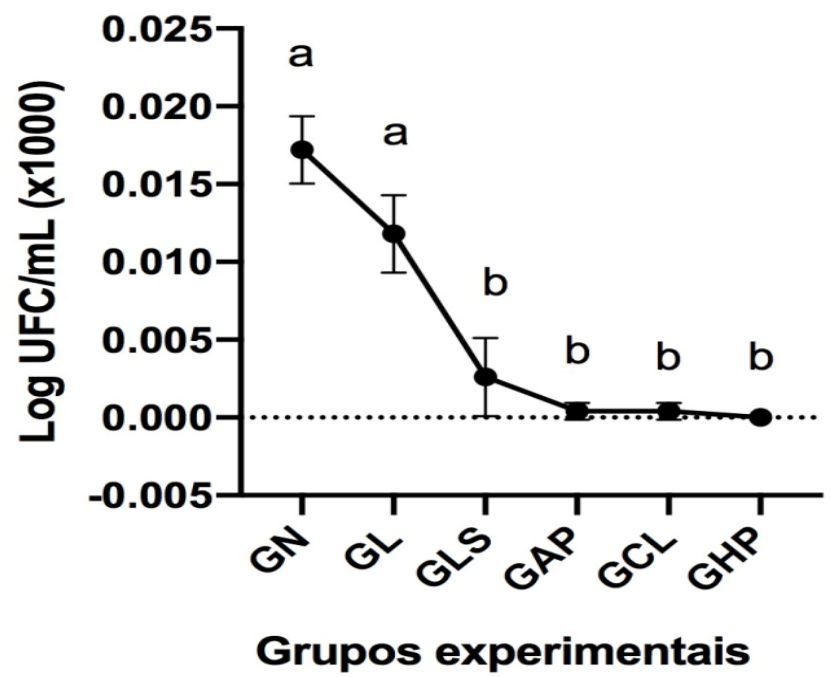

Legenda: Grupos experimentais: Controle Negativo (GN); Grupo Lavagem (GL); Grupo Lippiasidoides (GLS); Grupo Ácido Peracético 0,2\% (GAP); Grupo Digluconato de clorexidina 2\% (GCL); Grupo Hipoclorito de sódio $1 \%(G H P)$. *Letra a: significa diferença estatística significante entre os valores $(p<0,05)$. Letra b: significa diferença estatística não significante entre os valores $(p<0,05)$.

Fonte: Gomes AKP, et al., 2021.

Gráfico 2 - Quantidade de células (células $/ \mathrm{mL}$ ) de C. albicans ATCC 10231 após contaminação e tratamento com diferentes soluções desinfectantes em discos de alginato, após 5 dias (120 horas).

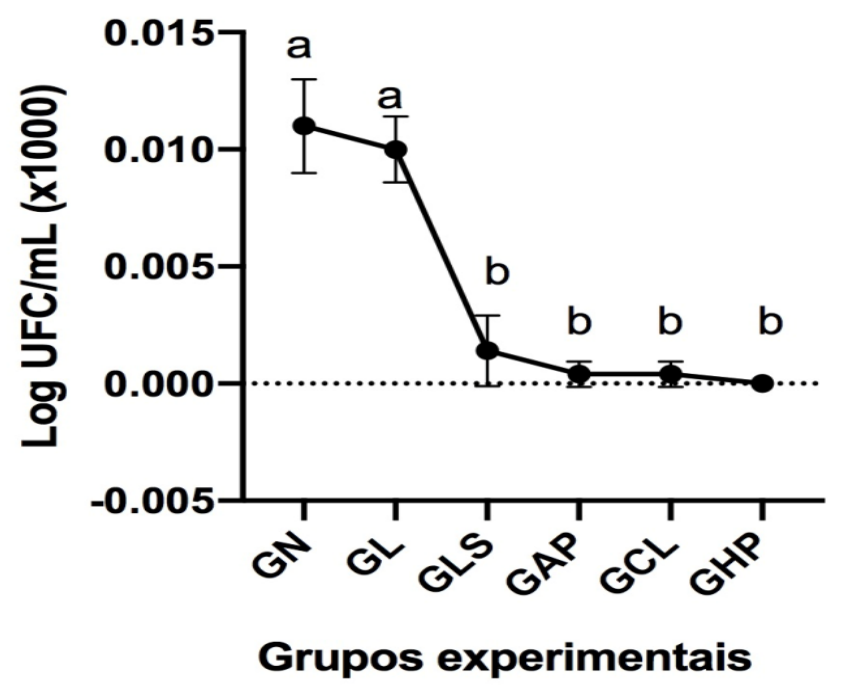

Legenda: Grupos experimentais: Controle Negativo (GN); Grupo Lavagem (GL); Grupo Lippiasidoides (GLS); Grupo Ácido Peracético 0,2\% (GAP); Grupo Digluconato de clorexidina 2\% (GCL); Grupo Hipoclorito de sódio $1 \%$ (GHP). *Letra a: significa diferença estatística significante entre os valores $(p<0,05)$. Letra b: significa diferença estatística não significante entre os valores $(p<0,05)$.

Fonte: Gomes AKP, et al., 2021.

\section{DISCUSSÃO}

Apesar da Odontologia estar sofrendo mudanças e haver a perspectiva de que no futuro, técnicas e materiais de moldagem possam ser substituídos por procedimentos de obtenção de imagens digitais em três dimensões (3D), atualmente, alguns procedimentos ainda são dependentes da obtenção de cópias fiéis de áreas da boca para o trabalho em laboratório (ULGEY M, et al., 2020; AL MORTADI N, et al., 2019; LEAL LKAM, et al., 2003). 
Este estudo avaliou quantitativamente a contaminação de moldes de hidrocoloide irreversível obtidos de pacientes e os efeitos dos métodos e soluções desinfetantes sobre a eficácia antimicrobiana, mostrando que houve crescimento bacteriano em todos os grupos controles (GN) e diminuição de microrganismos nos grupos experimentais.

Em 1996, o Conselho de Materiais Dentários da American Dental Association recomendou a desinfecção por spray para hidrocolóide irreversível, desinfecção por imersão para polissulfeto e silicone de adição, enquanto que para poliéter, a pulverização foi recomendada por 2 a 3 minutos (CHRISTENSEN GJ, 2009; OOSTHUYSEN J, et al., 2014).Alguns estudos concluíram que a eficácia da desinfecção por imersão é preferível, pois o desinfetante pulverizado tende a se agrupar e, portanto, todas as superfícies da impressão não são cobertas (ADA COUNCIL ON SCIENTIFIC AFFAIRS AND ADA COUNCIL ON DENTAL PRATICE, 1996).

Porém, outros estudos mostraram que a desinfecção por imersão provoca a expansão do molde de alginato, que é explicada pelo fenômeno da embebição, podendo prejudicar a fidelidade da moldagem (CHRISTENSEN GJ, 2009; OOSTHUYSEN J, et al., 2014). Além disso, há evidências de que, sob a forma de pulverização, os desinfetantes não causam alterações dimensionais significantes no modelo de gesso resultante (MERCHANT VA, et al., 1984; HIRAGUCHI H, et al., 2007). No entanto, ainda não há um consenso sobre qual a melhor forma de desinfecção e o método de escolha nesse estudo foi o de pulverização (spray) (MUZAFFAR D, et al., 2012).

Tanto o hipoclorito de sódio $1 \%$ quanto o ácidoperacético $0,2 \%$ foram eficazes na descontaminação dos moldes de hidrocoloide irreversível. Sabe-se que soluções contendo teor de cloro possuem capacidade antimicrobiana devido à formação de cloraminas, as quais são capazes de provocar alterações no metabolismo celular e destruir fosfolipídios pela ação oxidante e pela inibiçãoenzimáticairreversível nas bactérias (SEMENSATO AP, 2009; BABIKER GD, et al., 2018).

Apesar de não ser muito utilizado no meio odontológico, o ácidoperacético $0,2 \%$ tem sido considerado uma solução desinfetante segura por se decompor em substânciasnãotóxicas e nãomutagênicas (ácidoacético e oxigênio) e pornão ser alergênica. Além disso, essa solução é indicada para esterilização e desinfecção de alto nível devido ao alto poder germicida em baixas concentrações $(0,001 \%$ a $0,2 \%)$, agindo mesmo em presença de matériaorgânica. Sua ação microbicida se dá pelo seu alto poder oxidante sobre os componentes celulares (proteínas e enzimas), agindo sobre a membrana citoplasmática, pelo aumento de sua permeabilidade e desativando funçõesbiológicas, como a barreira osmótica (BABIKER GD, et al., 2018; ZAHRAA A, 2012; SVIDZINSKI AE, et al., 2007). Em virtude de sua eficiência comprovada, foi utilizado como referência de desinfecção no presente trabalho.

O spray de alecrim-pimenta (Lippiasidoidescham.) é uma solução de uso incipiente em Odontologia. No entanto, já existe estudo que comprova atividade antimicrobiana do óleo essencial do alecrim-pimenta e de seus principais componentes, timol e carvacrol, contra C. albicans e Streptococcus mutans (SOUZA JB, DANIEL LA, 2005). Recentemente, um estudo clínico controlado de curta duração mostrou efeito anti-placa da LippiasidoidesCham. comparável à solução de digluconato de clorexidina 0,12\% (BOTELHO MA, et al., 2007). Outros estudos clínicos afirmaram que o alecrim-pimenta foi seguro e eficaz na redução da placa bacteriana e inflamação gengival (RODRIGUES ISC, et al., 2013; BOTELHO MA, et al., 2007).

No presente estudo, não houve diferença estatística em relação à desinfecção do alginato imediata entre as soluções de alecrim-pimenta, ácido peracético, hipoclorito de sódio e digluconato de clorexidina, havendo poder fungicida comprovado. Tendo em vista o tempo de análise, as soluções são igualmente eficientes após 5 dias de desinfecção.

Alguns autores mostram que a lavagem dos moldes em água corrente após a moldagem remove a maior parte da sua contaminação juntamente com a saliva e o sangue superficial (CHRISTENSEN GJ, 2009). Porém, outros estudos mostram que para a descontaminação efetiva de superfícies contaminadas dos moldes de alginato é fundamental a desinfecção dessas impressões (PEREIRA SLS, et al., 2013; HERRERA SP, 
MERCHANT VA, 1996). No presente estudo, o grupo lavagem (GL) reduziu os microrganismos mas não significativamente em relação ao grupo controle $(\mathrm{CN})$. Esse achado mostra que a lavagem não teve ação antimicrobiana, sendo necessário o uso de algum agente desinfetante nos moldes de alginato.

A desinfecção dos moldes de forma eficaz e prática é de extrema importância no consultório odontológico, tendo em vista a constante troca de materiais entre cirurgião-dentista e técnico de prótese, aumentando assim, o risco de contaminação cruzada (AL MORTADI N, et al., 2019; OSÓRIO AM, 1998). Dentro das condições estudadas, o ácido peracético e o alecrim-pimenta se mostraram tão eficientes quanto o hipoclorito de sódio e o digluconato de clorexidina ao desinfetar o alginato contaminado com C. albicans, o que os torna possíveis métodos alternativo para a desinfecção de materiais odontológicos. Porém, é indicado avaliar o poder desinfetante desses agentes sobre outros microrganismos através de novas pesquisas. Além disso, são recomendados novos estudos que possam analisar alterações dimensionais do molde após desinfecção com alecrim-pimenta, sendo esta uma inovação na área que necessita de vasta pesquisa.

\section{CONCLUSÃO}

Considerando as limitações do estudo, pode-se concluir que o ácidoperacético $0,2 \%$, o óleo essencial da Lippiasidoides cham, o hipoclorito de sódio $1 \%$ e a clorexidina $2 \%$ mostraram-se bons agentes desinfetantes para moldes de hidrocoloides irreversíveis no método de pulverização, quando comparados ao grupo sem tratamento. Além disso, grupos apenas com lavagem inicial após contaminação não promoveram redução significativa dos microrganismos em questão. Com isso, sugere-se que se faz necessário realizar mais pesquisas comparativas de diferentes soluções e concentrações sobre outros microrganismos para que uma conclusão sobre métodos de desinfecção de hidrocolóides irreversíveis seja mais elucidativa.

\section{REFERÊNCIAS}

1. ADA Council on Scientific Affairs and ADA Council on Dental Practice. Infection control recommendations for the dental office and the dental laboratory. J Am Dent Assoc, 1996; 127: 672-68.

2. AL MORTADI N, et al. Disinfection of dental impressions: knowledge and practice among dental technicians. Clin Cosmetlnvestig Dent, 2019 7;11: 103-108.

3. AMALAN A, et al. Evaluation of the properties of irreversible hydrocolloid printing materials mixed with disinfectant liquids. Dent Res J (Isfahan), 2013; 10(1): 65-73.

4. BABIKER GH, et al. Dimensional Accuracy of Alginate Impressions Using Different Methods of Disinfection With Varying Concentrations. Compend Contin Educ Dent, 2018; 39(1): e17-e20.

5. BORGES LC. Ácido peracético: uma revolução na biossegurança. Rev APCD, 2006; (11): 4-5.

6. BOTELHO MA, et al. Antimicrobial activity of the essential oil from Lippiasidoides, carvacrol and thymol against oral pathogens. Braz Med Biol Res, 2007; 40(3): 349-56.

7. BOTELHO MA, et al. Effect of a novel essential oil mouthrinse without alcohol on gingivitis: a double-blinded randomized controlled trial. J Appl Oral Sci, 2007; 15(3): 175-80.

8. CHOUDHURY GK, et al. Disinfectant Efficacy of $0.525 \%$ Sodium Hypochlorite and Epimax on Alginate Impression Material. J Contemp Dent Pract, 2018; 19(1): 113-116.

9. CHRISTENSEN GJ. Impressions are changing: deciding on conventional, digital or digital plus in-office milling. J Am Dent Assoc Oct, 2009; 140(10): 1301-4.

10. CLINICAL AND LABORATORY STANDARDS INSTITUTE. Reference method for broth dilution antifungal susceptibility testing of yeasts - 3rd ed. CLSI document M27-A3 Clinical and Laboratory Standards Institute, Wayne, PA. 2008;22(15):454-460.

11. DASCHNER F. The hospital and pollution role of the hospital epidemiologist in protecting the environment. In: Wenzel R. Prevention and control of nosocomial infections. 3 ed. Williams and Wilkins. 1997;28.

12. DE FREITAS-PONTES KM, et al. Photosensitization of in vitro biofilms formed on denture base resin. J Prosthet Dent, 2014; 112: 632-637.

13. DE VASCONCELLOS AJ, et al. Environmental $\mathrm{pH}$ influences Candida albicans biofilms regarding its structure, virulence and susceptibility to fluconazole. MicrobPathog, 2014; 69(70): 39-44.

14. GRAZIANO KU, et al. Limpeza, desinfecção, esterilização de artigos e anti-sepsia. In: Infecção hospitalar e suas interfaces na área da saúde. São Paulo: Atheneu, 2000;266-304.

15. GUIRALDO RD, et al. Surface detail reproduction and dimensional accuracy of stone models: influence of disinfectant solutions and alginate impression materials. Braz Dent J, 2012; 23(4): 417-21.

16. HERRERA SP, MERCHANT VA. Dimensional stability of dental impressions after disinfection by immersion. Am Dent Assoc, 1986; 113(3): 419-22. 
17. HIRAGUCHI $\mathrm{H}$, et al. Effects of disinfection of combined agar/alginate impressions on the dimensional accuracy of stone casts. Dent Mater J, 2007; 26: 457-462.

18. JUNEVICIUS J, et al. Transmissão de microrganismos de dentistas para técnicos de laboratório de prótese dentária por meio de moldes dentais contaminados. Stomatol Baltic Dent Maxillofac J, 2004; 6: 20-3.

19. KAKATKAR VR. Técnicas de moldagem de próteses totais praticadas por dentistas particulares: uma pesquisa. J Indian ProsthodontSoc, 2013; 13: 233-5.

20. LEAL LKAM, et al. Análise de timol por CLAE na tintura de Lippiasidoides Cham. (alecrim-pimenta) Apresentação em diferentes categorias de desenvolvimento da planta. Rev Bras Farmacogn, 2003; 13; 09-11.

21. MARION J, et al. Chlorhexidine and its applications in endodontics: a literature Review. Dental press endod, 2013;3(3): 36-54.

22. MATOS FJA, OLIVEIRA F. Lippiasidoides Cham. - Farmacognosia, química e farmacologia. Rev Bras Farm, 1998; 79: 84-87.

23. MEIRA DM, et al. Influência do tempo na desinfecção de alginato contaminado com Staphylococcus aureus em ácido peracético ou gluataraldeído. R Fac Odontol P Alegre, 2011; 52(1): 11-14.

24. MERCHANT VA, et al. Preliminary investigation of a method for disinfection of dental impressions. J Prosthet Dent, 1984; 52(6): 877-879.

25. MINAGI S, et al. Disinfection method for impression materials: Freedom from fear of hepatitis B and acquired immunodeficiency syndrome. J Prosthet Dent, 1986; 56(4): 451-454.

26. MUZAFFAR D, et al. The effect of disinfecting solutions on the dimensional stability of dental alginate impression materials. Dent Mater, 2012; 28(7): 749- 755.

27. OOSTHUYSEN J, et al. Compliance with infection prevention and control in oral health care facilities: a global perspective. Int Dent J, 2014; 64(6): 297-311.

28. OSÓRIO AM. Avaliação da eficácia de agentes químicos na desinfecção de moldes de alginato. $R$ FacOdontol $P$ Alegre, 1998; 39(1): 17-19.

29. PASCUAL ME, et al. Lippia: traditional uses, chemistry and pharmacology: a review. J Ethnopharmacol, 2001; 76(3): 201-14.

30. PEREIRA SLS, et al. Clinical effect of a gel containing Lippiasidoides on plaque and gingivitis control. Eur J Dent, 2013; 7(1): 28-34.

31. PUNJ A, et al. Materiais e técnicas de moldagem dentária. Dent Clin North Am, 2017; 61: 779-96.

32. REUGGEBERG FA, et al. Sodium hypochlorite disinfection of irreversible hydrocolloid impression material. J Prosthet Dent, 1992; 67(5): 628-631.

33. RODRIGUES ISC, et al. Effect of Lippiasidoides in mouthrinses on de novo plaque formation: A double-blind clinical study in humans. Indian J Dent Res, 2013; 24(5): 533-6.

34. SEMENSATO AP, et al. Evaluation of the antimicrobial activity and dimensional alterations of alginate impression disinfectants. Eur J ProsthodontRestor Dent, 2009; 17(3): 121-25.

35. SOUZA JB, DANIEL LA. Comparison between sodium hypochlorite and peracetic acid for $E$. coli, coliphages and $C$. perfrigens inactivation of high organic matter concentration water. Rio de Janeiro: EngenhariaSanitária e Ambiental, 2005; 10: 2.

36. STAMPI S, et al. Evaluation of the efficiency of peracetic acid in the disinfaction of sewage effluentes. J appl Microbiol, 2001; 91(5): 833-8.

37. STAMPI S, et al. Peracetic acid as an alternative wastewater disinfectante to chlorine dioxide. J appl Microbiol, 2002; 93(5): 725-31.

38. SVIDZINSKI AE, et al. Eficiência do ácido peracético no controle de Staphylococcus aureus meticilina resistente. CiencCuidaSaúde, 2007; 6(3): 312-8.

39. ULGEY M, et al. Importance of disinfection time and procedure with different alginate impression products to reduce dimensional instability. Niger J Clin Pract, 2020; 23(3): 284-290.

40. ZAHRAA A. Comparison of antimicrobial activities and compressive strength of alginate impression materials following disinfection procedure. J Contemp Dent Prac, 2012; 13(4): 431-5. 